\title{
Increase Performance of IPMSM by Combination of Maximum Torque per Ampere and Flux-Weakening Methods
}

\author{
Saman Toosi, ${ }^{1}$ Mohammad Rezazadeh Mehrjou, ${ }^{1,2}$ \\ Mahdi Karami, ${ }^{1,3}$ and Mohammad Reza Zare ${ }^{1,4}$ \\ ${ }^{1}$ Department of Electrical and Electronic Engineering, Universiti Putra Malaysia, Selangor, Malaysia \\ ${ }^{2}$ Department of Electrical Engineering, Research and Science Branch, Islamic Azad University, Kerman, Iran \\ ${ }^{3}$ Department of Electrical and Electronic Engineering, Islamic Azad University, Bushehr Branch, Bushehr, Iran \\ ${ }^{4}$ Department of Electrical and Electronic Engineering, Islamic Azad University, Majlesi Branch, Majlesi, Iran
}

Correspondence should be addressed to Saman Toosi; saman_tosi_e@yahoo.com

Received 31 May 2013; Accepted 5 July 2013

Academic Editors: V. Fernao Pires and A. Gaouda

Copyright (C) 2013 Saman Toosi et al. This is an open access article distributed under the Creative Commons Attribution License, which permits unrestricted use, distribution, and reproduction in any medium, provided the original work is properly cited.

\begin{abstract}
Interior permanent magnet motor (IPMSM) was used as air conditioner compressor to reduce the power consumption and improve the performance of the system. Two control methods including maximum torque per ampere (MTPA) and flux-weakening methods were employed to increase the speed range of the air conditioner compressor. The present study adapted the flux weakening algorithm technique which can be used for constant torque and constant power regions. Results indicated that the operation speed range of the IPMSM may increase significantly by using the proposed flux weakening algorithm.
\end{abstract}

\section{Introduction}

Over the past few years, the environmental problem has grown dramatically worldwide, therefore most researcher spend the majority of their time to developed energy efficient motor drives for the house application and industry. In recent decade the interior permanent magnet synchronous motor (IPMSM) has become the most useful drive in modern speed control [1]. The IPMSM is becoming popular because of its beneficial features such as high power factor, high power density, and fast dynamic response [2-4].

Many researchers published in simulation, modeling, and also analysis of IPMSM drive for control and determining the speed of an IPMSM [5, 6]. One of the major applications of IPMSM is air conditioner [7]. As the air condition is high power consumption, permanent magnet motor can reduce power consumption and consequently reduce the energy bills [8]. The IPMSM saves up to $50 \%$ of the energy for air conditioners [9]. The air conditioner units often used by households and small business buildings include a condenser fan, an air handler fan, and a compressor. The compressor consumes $80 \%$ of the total inverse, $20 \%$ for two fans of total power under normal operating conditions. Therefore, IPMSM for air conditioner compressor that pumps up to $3.7 \mathrm{KW}$ has been used as an industrial standard of the world air conditioner manufacturing like Mitsubishi, Toshiba, LG, and Samsung [10].

The principle of energy efficient air condition system is to use variable speed drive to keep the temperature of area at desired temperature. Several different methods have been used to develop an efficient speed controller for IPMSM.

Rahman et al. (1998) have reported a flux-weakening mode based torque controller of IPMSM drive for operation on the exceeding base speed. The drive has not been tested for variable speed operations [11].

Hoque et al. (2002) have proposed a vector control strategy based on maximum torque per ampere (MTPA) scheme for the IPMSM drive. They obtained the $d$-axis command current from $q$-axis command current by use of a Taylor series expansion. A PI-based controller has been used [12].

Hossain et al. (2004) have reported simplified algorithm for flux-weakening speed control of IPMSM drives above the base speed. They presented the new approach for operating the IPMSM above the base speed. They have been derived 
and incorporated nonlinear expressions of $d$-axis and $q$-axis currents in a practical form for the flux-weakening strategy to solve the problem due to examine calculation requirement of the digital signal processor (DSP). They simplified expressions of $d$-axis and $q$-axis currents by using curve fitting method. The control algorithm for IPMSM drive system is efficient enough to operate in unload and full loading conditions [13].

Uddin and Abera (2009) have developed a model based efficiency optimization control algorithm for vector-controlled IPMSM variable speed drive. They optimized the efficiency of IPMSM online based on minimize losses of the IPMSM in a closed loop vector control with utilized $d$-axis armature current. They tested performance of the proposed optimization algorithm that has in both simulation and experiment on different operating conditions [14].

Meyer and Böcker (2006) have presented a concept for optimum control strategy of interior permanent magnet synchronous motors (IPMSM) drive in the constant torque region when the speed is lower than rated speed as well as above rated speed when the motor is working in the fluxweakening region. They also described the modeling of the IPMSM, loss minimal operation of an IPMSM considering current and flux constraints. They divided the operation region of the IPMSM into three main regions, constant torque range, partial field weakening ranges and full field weakening range. They provide the optimal $d$ and $q$ axes current set point for a reference torque and flux limit. The study shows that the torque from the MTPF control is bigger than torque from the MTPA control scheme at the same speed in the above rated speed region. They utilized look-up table as a base where the saturation effects can be considered. They have investigated the response of the drive using theory [15].

Vaclavek and Blaha (2008) have investigated an analytical solution of the maximum torque per flux strategy for IPMSM drive at the wide speed range. They revealed that in high torque demand when motor worked in the low speed region, the control will be influenced by the stator current, but in the high-speed region the drive control will be affected more by the stator voltage limitation than current. They developed a new algorithm with adaptability to various drives that was built from the knowledge of the drive electrical parameters. They find out the proper calculation procedure for stator current components which can apply to the control system in a wide speed range [16].

\section{Mathematical Model of IPMSM}

The following assumptions are taken before the IPMSM that model is developed in order to utilize the less complex linear behavior of the electrical system.

(a) Balanced three-phase stator windings are assumed.

(b) Saturation is neglected.

(c) The induced EMF is sinusoidal.

(d) Hysteresis losses and eddy currents are negligible.

Based on assumptions, mathematical model of the IPMSM can be derived from the standard model of the synchronous motor by removing the equation related to the field current and other associated terms because in the IPMSM the field excitation is provided by permanent magnets instead of a wire-wound dc rotor field [17]. The mathematical model is as follow:

$$
\left[\begin{array}{l}
\psi_{a m} \\
\psi_{b m} \\
\psi_{c m}
\end{array}\right]=\psi_{m}\left[\begin{array}{c}
\sin _{\theta_{r}} \\
\sin \left(\theta_{r}-\frac{2 \pi}{3}\right) \\
\sin \left(\theta_{r}+\frac{2 \pi}{3}\right)
\end{array}\right]
$$

where $\psi_{a m}, \psi_{b m}$, and $\psi_{c m}$ are the $a, b$, and $c$ phase stator flux linkages and the $\psi_{m}$ is the constant flux supplied by the permanent magnets, and $\theta_{r}$ is the rotor position angle.

The total air gap flux linkage of the three phases is the summation of the flux linkages due to the self-inductance of the corresponding phase current, the mutual flux linkages due to currents in the other phases, and the flux linkages in the three-phase stator winding due to PM of the rotor. The air gap flux linkages of the three phases are given as [17]

$$
\left[\begin{array}{l}
\psi_{a} \\
\psi_{b} \\
\psi_{c}
\end{array}\right]=\left[\begin{array}{ccc}
L_{a a} & M_{a b} & M_{a c} \\
M_{b a} & L_{b b} & M_{b c} \\
M_{c a} & M_{c b} & L_{c c}
\end{array}\right]\left[\begin{array}{c}
i_{a} \\
i_{b} \\
i_{c}
\end{array}\right]+\psi_{M}\left[\begin{array}{c}
\sin _{\theta_{r}} \\
\sin \left(\theta_{r}-\frac{2 \pi}{3}\right) \\
\sin \left(\theta_{r}+\frac{2 \pi}{3}\right)
\end{array}\right],
$$

where $\psi_{a}, \psi_{b}$, and $\psi_{c}$ are the air gap flux linkages; $L_{a a}, L_{b b}$, and $L_{c c}$ are the self-inductances, and $M_{a b}, M_{a c}, M_{b a}, M_{b c}$, $M_{c a}$, and $M_{c b}$ are the mutual inductances of phases $a, b$, and $c$, respectively. Now, the voltage equations of each phase of the IPMSM can be described as follows. In order to model the fields produced by the stator windings in terms of windings current,

$$
\begin{aligned}
& V_{a}=r_{a} i_{a}+\frac{d \psi_{a}}{d t}, \\
& V_{b}=r_{b} i_{b}+\frac{d \psi_{b}}{d t}, \\
& V_{c}=r_{c} i_{c}+\frac{d \psi_{c}}{d t},
\end{aligned}
$$

where $V_{a}, V_{b}$, and $V_{c}$ are the three-phase voltages, $i_{a}, i_{b}$, and $i_{c}$ are the three-phase currents, and $r_{a}, r_{b}$, and $r_{c}$ are the three-stator phase resistances. The Equation (3) can also be expressed in matrix form as below [17]:

$$
\left[\begin{array}{l}
V_{a} \\
V_{b} \\
V_{c}
\end{array}\right]=\left[\begin{array}{ccc}
r_{a} & 0 & 0 \\
0 & r_{b} & 0 \\
0 & 0 & r_{c}
\end{array}\right]\left[\begin{array}{l}
i_{a} \\
i_{b} \\
i_{c}
\end{array}\right]+p\left[\begin{array}{l}
\psi_{a} \\
\psi_{b} \\
\psi_{c}
\end{array}\right],
$$

where $p$ is the time differential operator $(d / d t)$. In order to avoid complexity of calculation, all of the equations can be transformed to the synchronously revolving rotor reference frame, so that the machine equations become independent of 
the rotor position. The core of field oriented control (FOC) is the projection of a three phases $(a, b$, and $c)$ time- and speeddependent system into two coordinates $(d, q)$ time-invariant system. Choosing a $(d, q)$ frame where the $d$ axis has the same direction of rotor magnet flux $\psi_{M}$, it is possible to verify that the produced electromagnetic torque is proportional to the magnet flux and the quadrature-axis stator current component (torque-producing stator current $i_{q}$ ). These transformations can be accomplished in two steps [18]. First $v_{a}, v_{b}$, and $v_{c}$ will be transformed from the stationary $a-b-c$ frame into the stationary $d-q$ frame and then from the stationary $d-q$ frame to the synchronously rotating $d^{r}-q^{r}$ excitation frame. The transformed phase variables in the stationary $d-q-0$ axis can be written in matrix form as [17]

$$
\left[\begin{array}{l}
X_{a} \\
X_{b} \\
X_{c}
\end{array}\right]=\left[\begin{array}{ccc}
\cos \theta_{r} & \sin \theta_{r} & 1 \\
\cos \left(\theta_{r}-\frac{2 \pi}{3}\right) & \sin \left(\theta_{r}-\frac{2 \pi}{3}\right) & 1 \\
\cos \left(\theta_{r}+\frac{2 \pi}{3}\right) & \sin \left(\theta_{r}+\frac{2 \pi}{3}\right) & 1
\end{array}\right]\left[\begin{array}{c}
X_{q} \\
X_{d} \\
X_{0}
\end{array}\right]
$$

The corresponding Park's transformation is

$$
\begin{aligned}
& {\left[\begin{array}{l}
X_{q} \\
X_{d} \\
X_{0}
\end{array}\right]} \\
& \quad=\frac{2}{3}\left[\begin{array}{ccc}
\cos \theta_{r} & \cos \left(\theta_{r}-\frac{2 \pi}{3}\right) & \cos \left(\theta_{r}+\frac{2 \pi}{3}\right) \\
\sin \theta_{r} & \sin \left(\theta_{r}-\frac{2 \pi}{3}\right) & \sin \left(\theta_{r}+\frac{2 \pi}{3}\right) \\
\frac{1}{2} & \frac{1}{2} & \frac{1}{2}
\end{array}\right]\left[\begin{array}{c}
X_{a} \\
X_{b} \\
X_{c}
\end{array}\right],
\end{aligned}
$$

where $X_{0}$ is the zero-sequence components. The matrix $X$ may represent either voltage or current. The rotor angle or rotor position is given by

$$
\theta_{r}=\int_{0}^{t} \omega_{r}(t) d t+\theta_{r}(0)
$$
[19]

The mechanical torque of IPMSM can be represented by

$$
T=\frac{3}{2} P(\underbrace{\psi_{\text {torque }}^{\psi_{m} I_{q}^{r}}}_{\begin{array}{c}
\text { Electromagnetic Reluctance } \\
\text { torque }
\end{array}}+\underbrace{\left(L_{d}-L_{q}\right) I_{d}^{r} I_{q}^{r}}), \quad L_{q}>L_{d},
$$

where $\psi_{m}$ is the permanent magnet flux linkage, $L_{d}, L_{q}$ are inductance components of stator winding, $I_{d}, I_{q}$ are current components, and $p$ is the number of pole pairs.

\section{Methodology}

Due to the nonlinear nature of IPMSM, both the magnitude and the angles of the current vectors need to be controlled. For this reason, the traditional scalar control is not suitable for high performance drive applications of IPMSM, but vector control technique will be an appropriate choice. The vector control scheme incorporating the speed controller and the current controller is used for the IPMSM drive. Vector control scheme is used in the proposed flux-weakening algorithm for speed control of IPMSM drive to decouple the torque and flux generating currents. Thus providing faster and smoother transient responses.

3.1. Principle of Drive System. The IPMSM drive for high performance application consists, basically, of four main parts: the electrical motor, three-phase inverter, the vector controller, and speed controller. The present study used the feedback control in order to force the motor to follow the command speed in vector controller scheme. The feedback will be consisting of the actual motor current and the rotor angular position. According to the ALC20CN model of wall mounted series from Acson's air conditioner, the compressor power is $1587 \mathrm{~W}$ so:

The electrical motor is a 230 volt, $1.65 \mathrm{~kW}$ IPMSM with $1200 \mathrm{rpm}$ rated speed. This motor has 6 poles and salient rotor [20].

The three-phase inverter is a voltage source inverter (VSI), controlled by pulse-width modulation. The pulsewidth modulation (PWM) forces the motor to follow the command speed forces by the actual motor currents to follow the command currents as closely as possible.

The speed controller generates the torque command from the command speed (error between command and actual speeds). It also computed the normalized flux value with speed of the motor in order to perform a flux-weakening control.

The torque from speed controller feed the vector controller, the command currents $i_{d}^{r *}$ and $i_{q}^{r *}$ are generated from the command torque, and the $i_{a}^{*}, i_{b}^{*}$, and $i_{c}^{*}$ are generated from $i_{q}^{r *}$ and $i_{d}^{r *}$ by using the reverse Park's transformation. From the difference between these command currents $\left(i_{a}^{*}, i_{b}^{*}\right.$, and $\left.i_{c}^{*}\right)$ and the actual motor currents $\left(i_{a}, i_{b}\right.$, and $\left.i_{c}\right)$, the appropriate operating gating signals are calculated for the 3-phase voltage source inverter due to the pulse-width modulation. An optimal control is minimizing the line current amplitude for the required torque when the nominal flux is needed. The vector controller also changed the phase and the amplitude of the current when a flux-weakening is required in order to extend the torque-speed operating range.

The conventional proportional integral (PI) controller is chosen in this study because its simplicity and fast response characteristics, although it pronounced sensitivity and fixed gain. Figure 1 describes a complete indirect vector control scheme for VSI-fed IPMSM drive [21].

3.2. Vector Control of IPMSM. The vector controller technique is an effective approach for control of $\mathrm{AC}$ motors in high performance drive application. The IPMSM control will become easy as DC motor by a decoupling control known as vector control (field oriented control). The vector control detaches the torque component of current and flux of the motor. Based on the vector control (VC) method, induction 


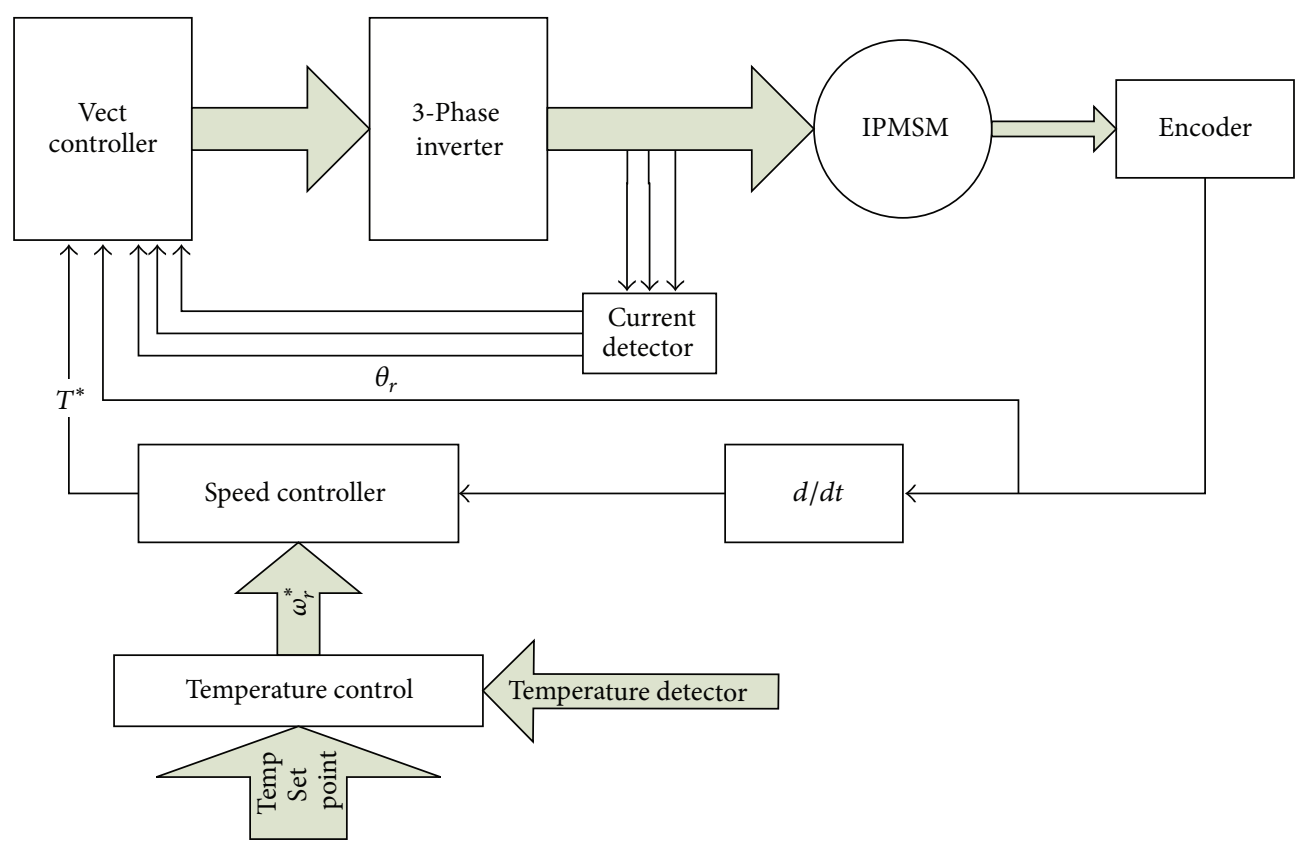

FIGURE 1: Block diagram of complete vector controlled VSI-fed IPMSM drive.

motor and synchronous motor can be control easily like separately excited AC motor by changing the orientation of magneto motive force (MMF) of stator or current vector that linked to the rotor flux. The constant torque and flux-weakening are the control options that we utilized in this study. These options have physical limitation in the inverter, and the motor related to the speed when the constant torque operation finishes and the flux-weakening starts. Figure 2 indicates the proportional between torque and speed in the constant torque operation and the constant power operation regions.

3.3. Constant Torque Operation. Due to limitation of the inverter such as output voltage, output current, and power capacity in the motor drive assume that the $V_{s \max }$ is allowable maximum phase voltage and $I_{s \max }$ is allowable maximum value of the line current. Thus, this study has [23]

$$
\begin{aligned}
& I_{d}^{r 2}+I_{q}^{r^{2}} \leq I_{s \max }^{2} \\
& v_{d}^{r^{2}}+v_{q}^{r 2} \leq v_{s \max }^{2} .
\end{aligned}
$$

In the constant, torque control regime the maximum possible torque is desired at all times. This is performed by making the $i_{d}$ current equal to zero and making the torque producing current $i_{q}$ equal to the supply current $I_{m}$. In the case where $I_{d}^{r}$ is equal to zero, the reluctance torque of IPMSM is not fully exploited. The torque equation (8) can be rewritten as

$$
T_{e}=\left(\frac{3 p}{2}\right) \psi_{m} \cdot i^{r} q
$$

Assume that

$$
\text { The } k_{t}=\left(\frac{3 p}{2}\right) \psi_{m}
$$

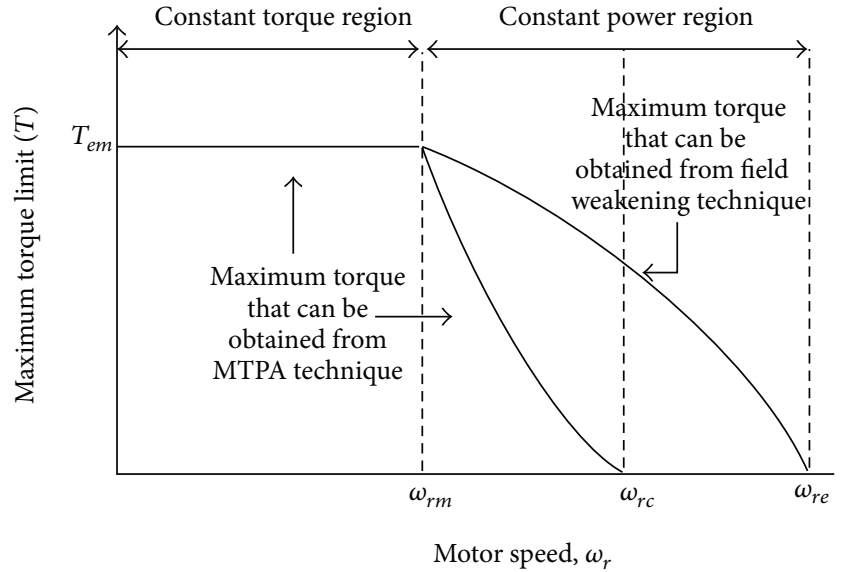

FIGURE 2: Maximum torque limit curve at different operating region [22].

The torque is given by

$$
\text { The } T_{e}=k_{t} \cdot i_{q}^{r} \text {. }
$$

Equation (11) indicates that the torque is depending on the motor current for fast transient response and low loss in the case where $I_{d}^{r}$ is not equal to zero. Thus the MTPA control is a good choice [22]. The basic principle of MTPA is that it minimized the line current amplitude for giving the maximum torque. For the MTPA control below the base speed, the $i_{d}^{r}$ can be calculated in terms of $i_{q}^{r}$ by differentiating from (8), so the torque will be

$$
T_{e M}=\frac{3 p}{2}\left\{\psi i_{q M}^{r}+\left(L_{d}-L_{q}\right) i_{q M}^{r} i_{d M}^{r}\right\},
$$


where

$$
i_{q M}^{r}=\sqrt{I_{s \max }^{2}-\left(i_{d M}^{r}\right)^{2}} .
$$

Figure 3 describes the trajectory of the MTPA and field weakening operation of IPMSM. The blue curve illustrates the maximum torque per ampere (MTPA) features, the blue dashed curve between points $\mathrm{A}-\mathrm{B}$ is the maximum torque per flux (MTPF) features, and the black hyperbolas, green ellipses, and red circles are torque, stator voltage limitation and current limitation, respectively.

The lowest distance of constant torque curve is the collide point of the constant torque curve with the MTPA curve from the origin point $(0,0)$. Achieving the desired torque with the lowest current needs to track the MTPA curve. When the motor speed that increases the rotor core becomes saturated to produce torque, the capability of the motor torque decreases rapidly. Thus flux control will become necessity even in the constant torque region to achieve maximum torque.

3.4. Flux-Weakening Operation. Due to the effect of the $d$-axis armature reactance on flux-weakening in IPM synchronous motor, the flux-weakening mode in the constant power operation can be utilized to control the IPM synchronous motor at high speed drive application. In the constant power region (above the rated speed), the motor operates with rated flux linkages where the ratio between the induced electromotive force (emf) and stator frequency $(V / f)$ is maintained constant. As DC voltage source that supplies the inverter is fixed, the $V / f$ ratio is reduced when the frequency goes above the rated frequency [19].

As depicted in Figure 3, the intersection point of voltage limit curve with constant torque gives the minimum current point to produce the required torque, and also Figure 2 illustrates that the torque produced at above rated speed region due to the MTPA technique is less than the torque produced by the flux-weakening technique.

The rotor flux of IPMSM is generated by permanent magnet which cannot be changed directly. Therefore, the principle of flux-weakening control of IPMSM is used to reduce air gap flux by increasing the negative direct axis of currents. The flux will be reduced equivalently due to reducing air gap flux and achieves the purpose of flux-weakening control [24].

The IPMSM torque is depending on the $d$-component of the stator current which is affected by the field weakening. The mechanical torque produced by IPMSM in the steady state can be described in (8) [19].

Vaclavek and Blaha (2008) found simplified algorithm for flux-weakening speed control of IPMSM drives above the base speed based on the coordinate system transformation from the stator current $I_{d}, I_{q}$ plane to the stator voltage $V_{d}, V_{q}$ plane. They identified an approach which is easily adapted to control drive by using the actual parameters, and also it requires low calculative power.

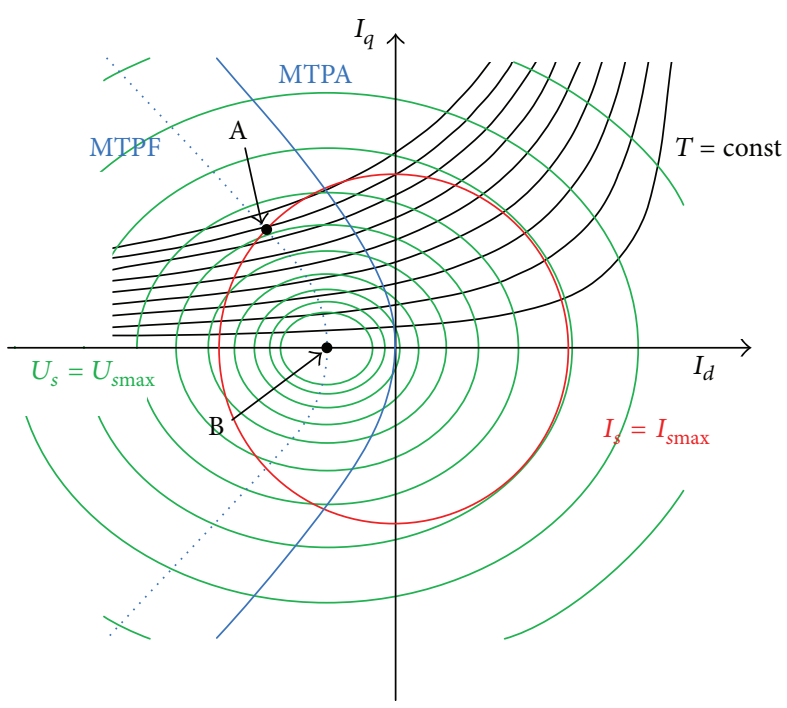

FIGURE 3: Field weakening characteristics [23].

According to this approach the steady-state current can be appraised from (8) in the terms of the stator voltage and currents can be calculated as

$$
\begin{aligned}
I_{d}= & f_{I_{d}}\left(\omega_{r e}\right) \\
= & \frac{L_{q}}{L_{q} L_{d}-L_{d}^{2}} \frac{\psi_{M}}{4}-\frac{\psi_{M}}{L_{d}} \\
& -\sqrt{\left(\frac{L_{q}}{L_{q} L_{d}-L_{d}^{2}} \frac{\psi_{M}}{4}\right)^{2}+\frac{1}{2}\left(\frac{V_{s \max }}{\omega_{r e} L_{d}}\right)^{2}},
\end{aligned}
$$

and thus

$$
\begin{aligned}
I_{q}^{2}= & \left(\frac{V_{s \max }}{\omega_{r e} L_{q}}\right)^{2} \\
& +\left[\frac{1}{4} \frac{\psi_{M}}{L_{q}-L_{d}}-\sqrt{\left(\frac{1}{4} \frac{\psi_{M}}{L_{q}-L_{d}}\right)^{2}+\frac{1}{2}\left(\frac{V_{s \max }}{\omega_{r e} L_{q}}\right)^{2}}\right]^{2} .
\end{aligned}
$$

Figure 4 indicates the block diagram of the purpose of flux-weakening computation; according to this block diagram the principle of field weakening scheme occurs when the stator voltage reaches the limit value. The stator voltage from $\sqrt{V_{d}^{2}+V_{q}^{2}}$ will be compared with the maximum allowed stator voltage $V_{s \max }$. Then the difference between the two data will be pass through the PI controller, and the output of the controller is the $i_{d}$ set point. The PI controller block provides the flux modification stator current component. $I_{d}$ is computed by (16), while the $i_{d}$ constraints are $I_{d} \in\left\langle I_{d} ; 0\right\rangle$ and with respect to machine electrical angular speed [23].

3.5. Mathematical Model of Air Conditioner. Equation (18) describes the mathematical model for air conditioner, where $\eta$ is an efficiency, $m$-dot is mass flow rate, $\omega$ is speed of 


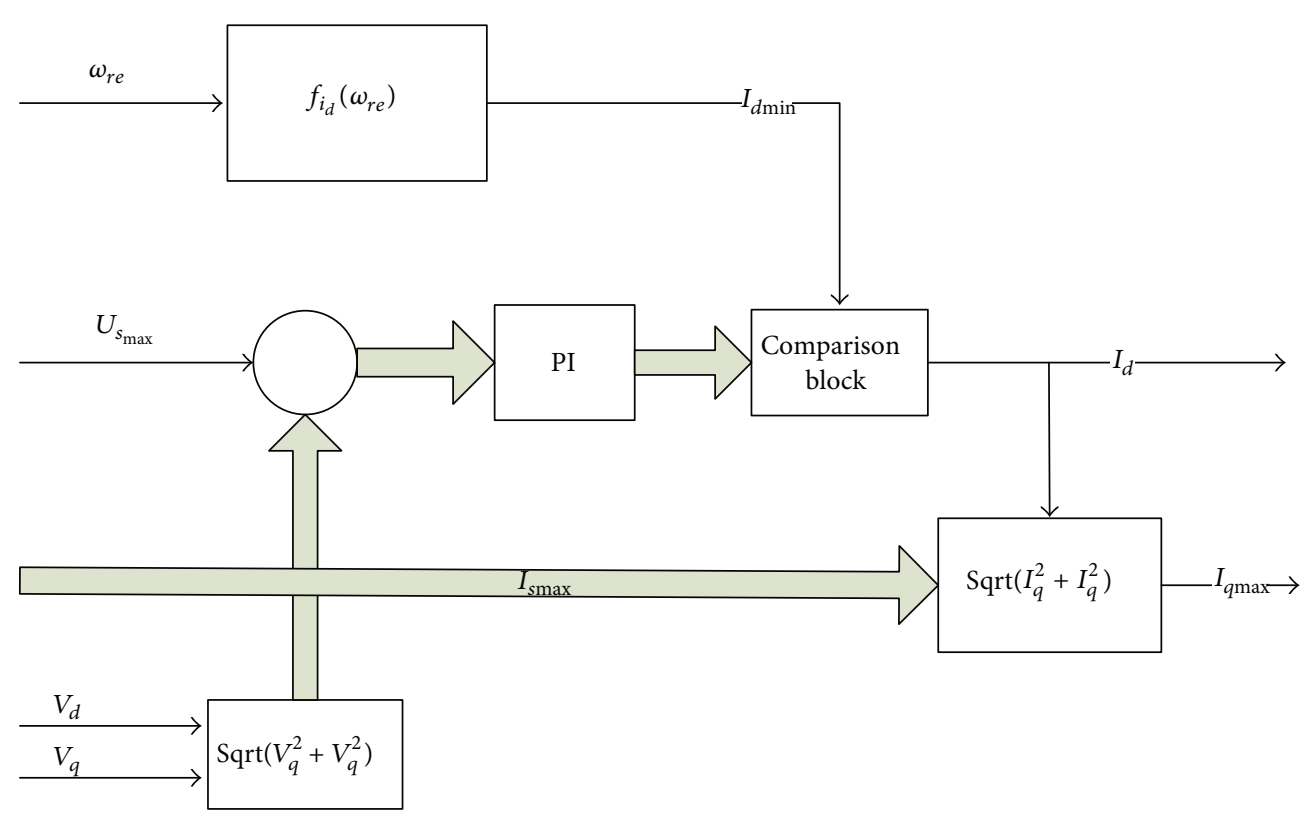

FIGURE 4: Block diagram of field weakening computation [22].

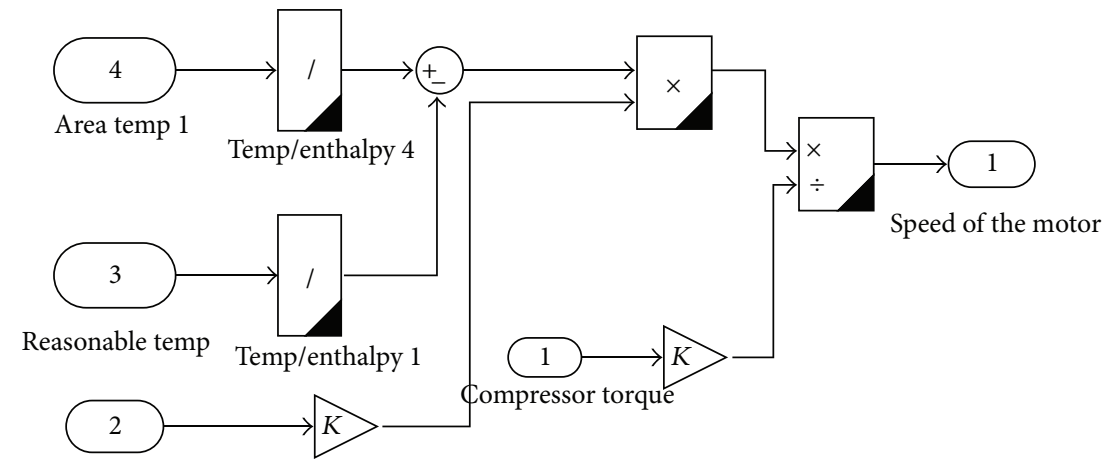

Blower speed proportion Max flow rate

FIGURE 5: Block diagram of speed calculation due to temperature.

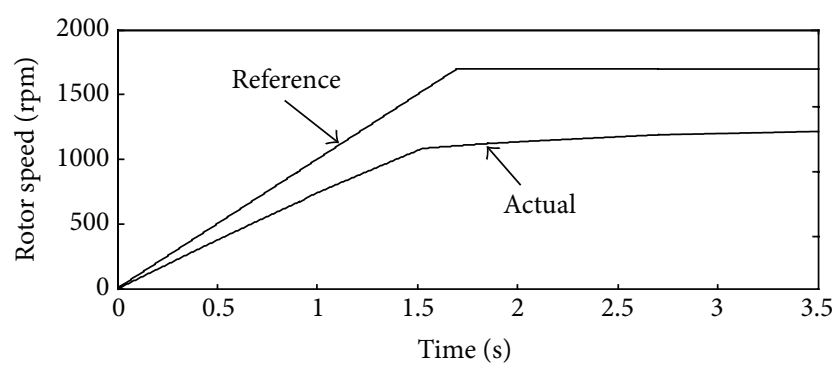

Figure 6: Maximum speed with conventional $i_{d}=0$ control.

motor, $T$ is compressor torque, and $h_{4}$ and $h_{1}$ are enthalpy related to the output temperature and references temperature, respectively [25] as follows:

$$
\eta *\left(\omega * T_{\text {comp }}\right)=m_{\text {dot }}\left(h_{4}-h_{1}\right)
$$

The block diagram of (18) in MATLAB is shown in Figure 5.

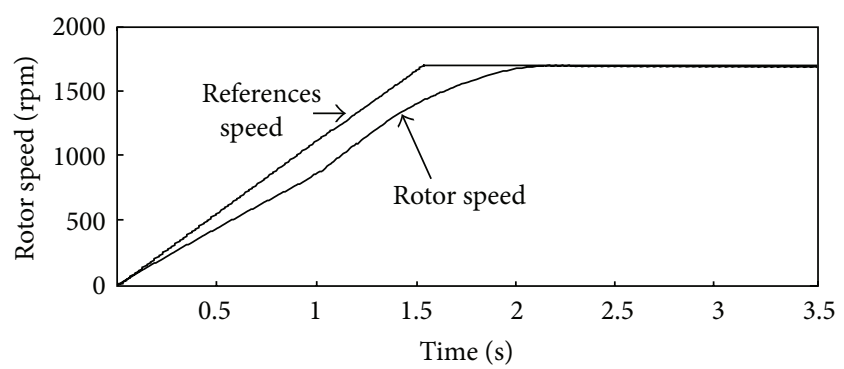

FIGURE 7: Maximum speed with proposed flux-weakening control.

As depicted in Figure 5 at the first step, the temperature converts from Centigrade to Kelvin, and then the output converts to enthalpy due to the look up table, after that the result of multiplication of the difference between two enthalpies at maximum flow rate (maximum flow rate is directly depends of blower speed) is divided to the result of multiplication of efficiency at compressor torque to find the reference speed of motor. 

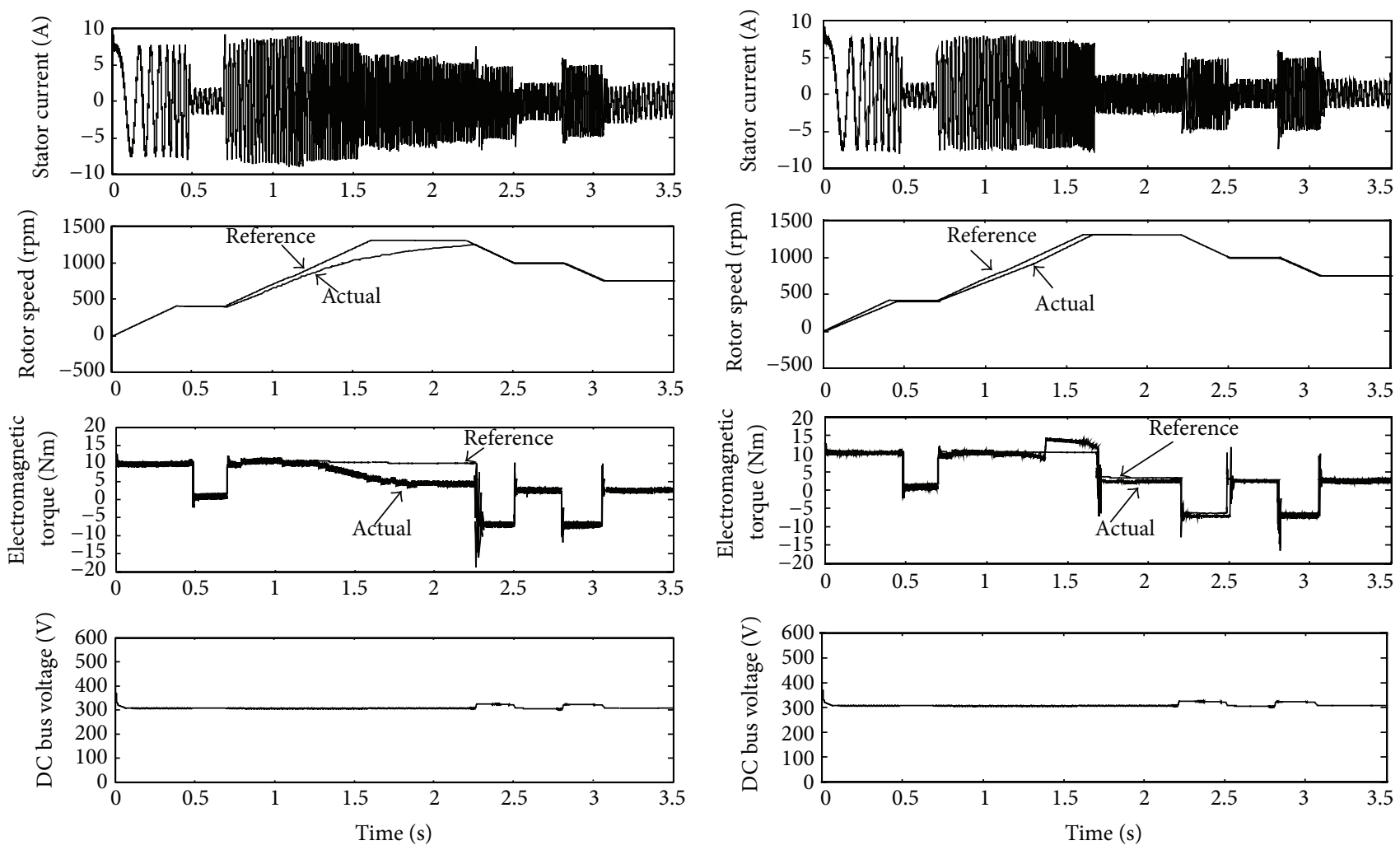

(a)

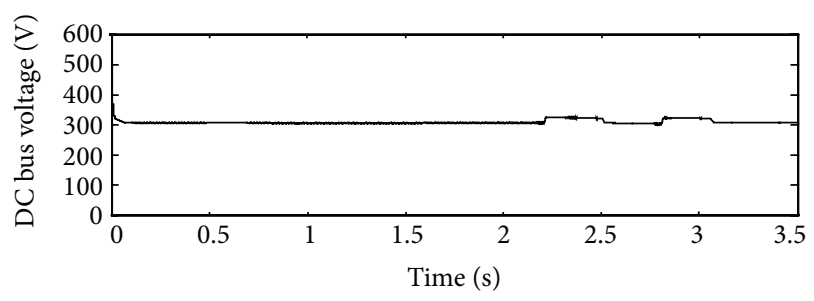

(b)

FIGURE 8: (a) Result of IPMSM drive with conventional $i_{d}=0$ controller. (b) Result of IPMSM drive with proposed flux-weakening control.

This references speed of motor can be used as input of propose IPMSM motor drive. The motor stator current, the rotor speed, the electromagnetic torque, and the DC bus voltage can be clearly seen on the scope.

\section{Result}

4.1. Maximum Speed. The IPMSM operated with two different speed control system, in order to find the maximum speed over the based speed $(1200 \mathrm{rpm})$. The simulation result of general $i_{d}=0$ control and flux-weakening control systems shown in Figures 6 and 7, respectively, in load of $2 \mathrm{Nm}$ conditions. In order to run the motor over the based speed, the command speed, specified at $1700 \mathrm{rpm}$. According to Figure 6 , the maximum speed is $1252 \mathrm{rpm}$ with the general $i_{d}=0$ control, while as shown in Figure 7 the maximum speed with flux-weakening control can reach $1700 \mathrm{rpm}$. Results are presented below.

Figures 6 and 7 illustrates the actual motor speed ability to follows the command speed which it is not acceptable in the case of $i_{d}=0$ and it can be reach to $1700 \mathrm{rpm}$ in the case of proposed flux-weakening control.

Due to limitation of speed in real motor, the $1350 \mathrm{rpm}$ (12.5\% above the synchronous speed of motor) is selected as a maximum speed for simulation. Three conditions have been tested on the proposed IPMSM drive system; sudden change in load, sudden change in speed, and ambient parameter variations.
4.2. Sudden Change in Speed. Figures 8(a) and 8(b) show the simulated responses of IPMSM drive with proposed control method, in the case of speed changing step by step.

In Figures 8(a) and 8(b), initially a step input of speed from zero to $400 \mathrm{rpm}$ is applied to both two control systems with a load of $2 \mathrm{Nm}$. In the second step at $t=0.7 \mathrm{~s}$, the command speed is increased from $400 \mathrm{rpm}$ to $1350 \mathrm{rpm}$, while a constant load is applied. In the next step at $t=2.2 \mathrm{~s}$, the command speed is decreased from $1350 \mathrm{rpm}$ to $1000 \mathrm{rpm}$. Finally, the command speed is decreased from $1000 \mathrm{rpm}$ to $750 \mathrm{rpm}$. Figures 8(a) and 8(b) show the speed response, torque response, stator current, and DC bus voltage of the IPMSM drive with the conventional $i_{d}=0$ controller and proposed flux-weakening controller, respectively.

It can be clearly seen from Figure 8(a) that the system is be able to follows the command speed, but it cannot reach $1350 \mathrm{rpm}$. The undershoot/overshoot and steady-state error exhibit electromagnetic torque, and stator current is not acceptable. As was shown in Figure 8(b), the speed response, torque response, stator current, and DC bus voltage of the IPMSM drive with proposed flux-weakening controller are acceptable for high performance drive application.

4.3. Variation in Load. Figures 9(a) and 9(b) show the simulated responses of IPMSM drive when the load changed below and above the based speed.

In Figures 9(a) and 9(b), initially a step input of speed from zero to $400 \mathrm{rpm}$ is applied with a load of $1 \mathrm{Nm}$, and then 

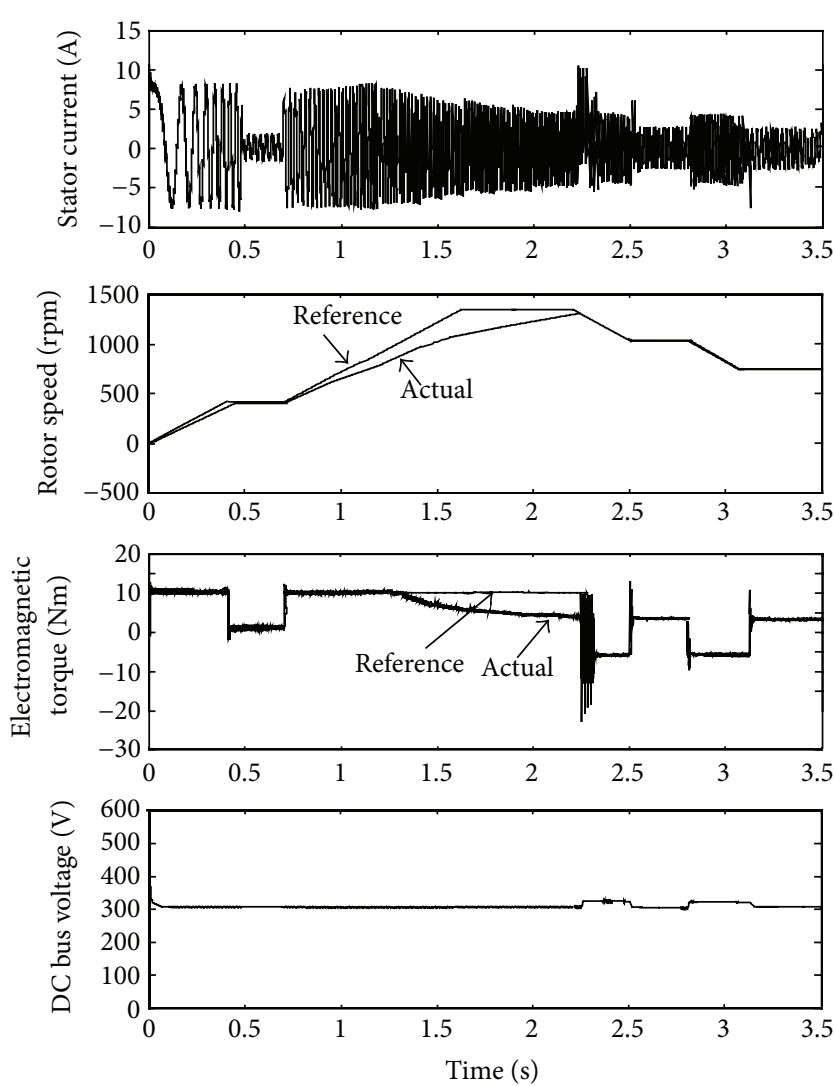

(a)
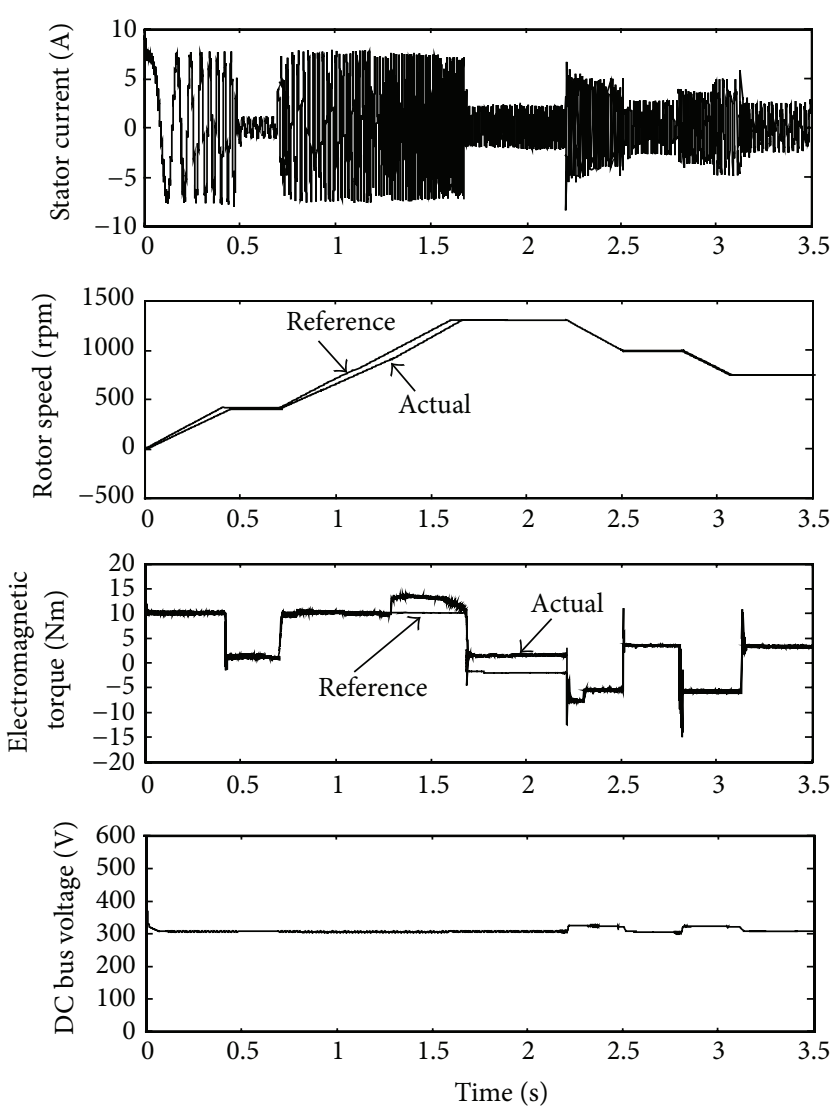

(b)

FIGURE 9: (a) Result of IPMSM drive with conventional $i_{d}=0$ controller. (b) Result of IPMSM drive with proposed flux-weakening control.

at time $t=0.8 \mathrm{~s}$ the load is increased from $1 \mathrm{Nm}$ to $3 \mathrm{Nm}$. In the second step at $t=0.7 \mathrm{~s}$, the command speed is increased from $400 \mathrm{rpm}$ to $1350 \mathrm{rpm}$, while a constant load of $3 \mathrm{Nm}$ is applied. Again at $t=1.2 \mathrm{~s}$, the load is decreased from $3 \mathrm{Nm}$ to $1 \mathrm{Nm}$. In the next step at $t=2.2 \mathrm{~s}$, the command speed is decreased from $1350 \mathrm{rpm}$ to $1050 \mathrm{rpm}$. Again at $t=2.3 \mathrm{~s}$, the load is increased from $1 \mathrm{Nm}$ to $3 \mathrm{Nm}$.

Finally, the command speed is decreased from $1050 \mathrm{rpm}$ to $750 \mathrm{rpm}$. Figure 9 (a) shows the speed response, torque response, stator current, and DC bus voltage of the IPMSM drive with the conventional $i_{d}=0$ controller. Figure 9(b) exhibits the speed response, torque response, stator current, and DC bus voltage with proposed flux-weakening control.

It can be clearly seen from Figure 9(a) that the speed and torque responses for the conventional controlled in the case of variation in load are not also acceptable. According to Figure 9(b), the overshoot/undershoot response of all parameter is suitable for driving the motor over the rated speed.

4.4. Variation in Ambient Parameters. The references temperature has restrictions between 16 and 29 degrees centigrade $\left({ }^{\circ} \mathrm{C}\right)$ for wall mounted.

The reference speed of motor calculates is based on (18) due to alternating on reference temperature and rate of load. Figure 10 describes the speed response, torque response, stator current, and DC bus voltage with proposed flux-weakening control.

In Figure 10, initially the $29^{\circ} \mathrm{C}$ as a reference temperature is applied with a load of $2 \mathrm{Nm}$ that means the speed goes up from zero to $492 \mathrm{rpm}$. In the second step at $t=0.7 \mathrm{~s}$, the command speed is increased from $492 \mathrm{rpm}$ to $1350 \mathrm{rpm}$ (selected the $16^{\circ} \mathrm{C}$ as a reference temperature), while a constant load of $2 \mathrm{Nm}$ is applied. Figure 10 indicates that during change the temperature from 29 to $16^{\circ} \mathrm{C}$, the references speed will be increased to $1450 \mathrm{rpm}$ due to (18), but the maximum speed is $1350 \mathrm{rpm}$, because of the maximum and minimum references speed which is defined as 1350 and $300 \mathrm{rpm}$, respectively, in MATLAB simulation. After that, at $t=0.8 \mathrm{~s}$, the load is increased from $2 \mathrm{Nm}$ to $3 \mathrm{Nm}$. So the speed goes down to $966 \mathrm{rpm}$. Again at $t=1.2 \mathrm{~s}$, the load is decrease from $3 \mathrm{Nm}$ to $1 \mathrm{Nm}$, and the speed goes up to $2900 \mathrm{rpm}$, while the reference speed remains at $1350 \mathrm{rpm}$. In the next step at $t=2.2 \mathrm{~s}$, the command temperature is increased from $16^{\circ} \mathrm{C}$ to $21^{\circ} \mathrm{C}$, and the command speed drops to $2100 \mathrm{rpm}$ while the references of motor still remain at the $1350 \mathrm{rpm}$ due to speed limitation of motor. Again at $t=2.3 \mathrm{~s} \mathrm{Nm}$ the speed goes down to $700 \mathrm{rpm}$ due to the increase of load from $1 \mathrm{Nm}$ to $3 \mathrm{Nm}$. And finally, the command speed is decreased from $700 \mathrm{rpm}$ to $484 \mathrm{rpm}$ (selected the $25^{\circ} \mathrm{C}$ as a reference temperature). Result of simulation presented on Figure 10 indicates that 

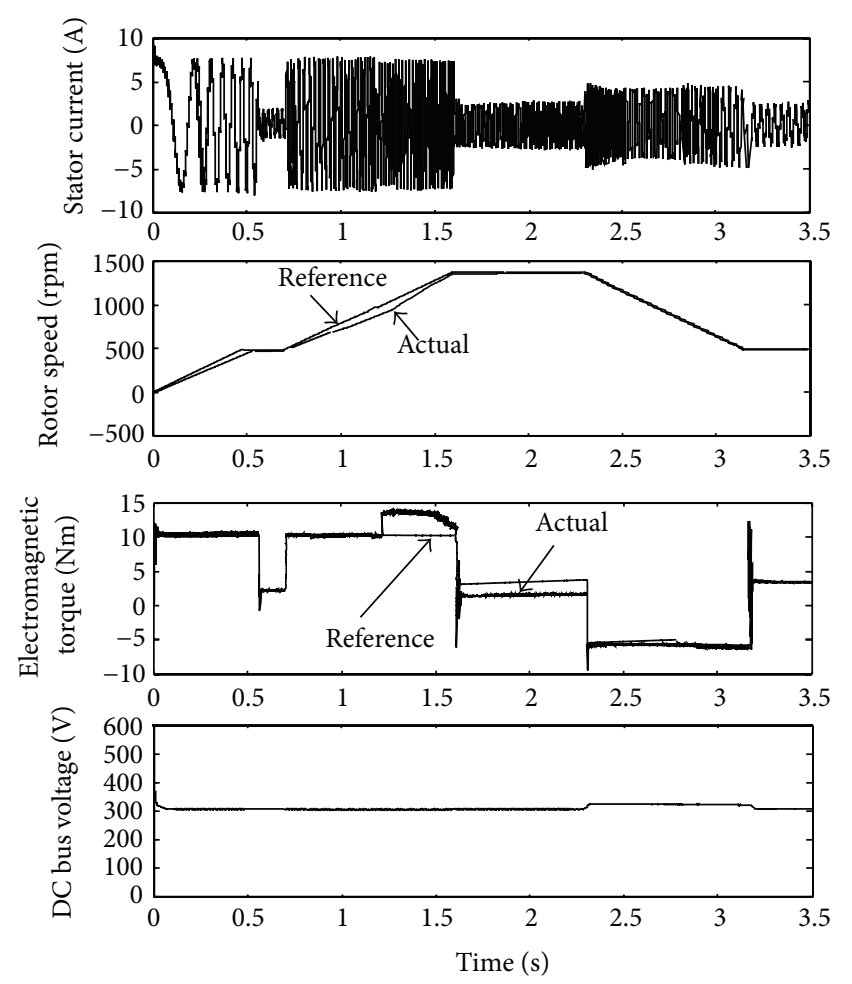

FIGURE 10: Result of IPMSM drive with proposed flux-weakening control for air conditioner.

undershoot/overshoot and steady-state error of the fluxweakening control system is acceptable for proposed air conditioner system.

\section{Conclusion}

The present study revealed the validity of the control system in different dynamic operating conditions which is applied to drive the IPMSM over the rated speed. Finding of this study indicated that the operation speed range of the IPMSM may be increased significantly by using the proposed flux-weakening algorithm.

In this study the performance of the IPMSM as air conditioner compressor has been investigated with using the maximum torque per ampere (MTPA) and flux-weakening (FW). MTPA is applied to the system when the compressor operates at based speed and below (constant torque region); FW applied to the system when compressor operates at constant power region (above base speed). The proposed flux-weakening has been simulated along with a convectional MTPA $\left(i_{d}=0\right)$ for comparison purpose.

The developed flux-weakening control algorithm concludes the optimum $d$-axis current of the system for a torque command and given speed with good response and slightly torque ripple. The control system has been tested at different operating conditions: unexpected load change, command speed influence, and ambient parameter change. The proposed method has also been compared with the conventional $i_{d}=0$ control scheme. The proposed control system has been found to be robust, efficient for air conditioner with quickly response to speed changes and precise.

\section{References}

[1] Z. Yunusa, A. Dan-Isa, Y. A. Sai'd et al., "Effects of the number of rules on the quality of fuzzy logic control of induction motor," International Journal of Applied Electronics in Physics \& Robotics, vol. 1, pp. 14-17, 2013.

[2] A. Consoli and A. Abela, "Transient performance of permanent magnet AC motor drives," IEEE Transactions on Industry Applications, vol. 22, no. 1, pp. 32-41, 1986.

[3] T. M. Jahns, G. B. Kliman, and T. W. Neumann, "Interior permanent-magnet synchronous motors for adjustable-speed drives," IEEE Transactions on Industry Applications, vol. 22, no. 4, pp. 738-747, 1986.

[4] K. Nakamura, K. Saito, and O. Ichinokura, "Dynamic analysis of interior permanent magnet motor based on a magnetic circuit model," IEEE Transactions on Magnetics, vol. 39, no. 5, pp. 32503252, 2003.

[5] C. Jo, J.-Y. Seol, and I.-J. Ha, "Flux-weakening control of IPM motors with significant effect of magnetic saturation and stator resistance," IEEE Transactions on Industrial Electronics, vol. 55, no. 3, pp. 1330-1340, 2008.

[6] H. M. Kojabadi and G. Ahrabian, "Simulation and analysis of the interior permanent magnet synchronous motor as a brushless AC-drive," Simulation Practice and Theory, vol. 7, no. 7, pp. 691-707, 2000.

[7] D. M. Lonel, Brushless Interior Permanent Magnet (IPM) Motors A New Solution for High Performance Appliances, A.O.smith corporate technology center, Milwaukee, 2008.

[8] A. Sathyan, N. Milivojevic, Y.-J. Lee, M. Krishnamurthy, and A. Emadi, "An FPGA-based novel digital PWM control scheme for BLDC motor drives," IEEE Transactions on Industrial Electronics, vol. 56, no. 8, pp. 3040-3049, 2009.

[9] B. Argüello-Serrano and M. Vélez-Reyes, "Nonlinear control of a heating, ventilating, and air conditioning system with thermal load estimation," IEEE Transactions on Control Systems Technology, vol. 7, no. 1, pp. 56-63, 1999.

[10] N. Lu, Y. L. Xie, Z. Huang et al., Air Conditioner Compressor Performance Model, Uinted states department of energy, 2008.

[11] M. F. Rahman, L. Zhong, and K. W. Lim, "A direct torquecontrolled interior permanent magnet synchronous motor drive incorporating field weakening," IEEE Transactions on Industry Applications, vol. 34, no. 6, pp. 1246-1253, 1998.

[12] M. Hoque et al., "A novel approach for MTPA speed control of IPMSM drive," in Proceedings of 2nd IEEE International Conference of Electrical \& Computer Engineering, pp. 26-27, 2002.

[13] M. J. Hossain, M. S. Hossain, M. A. Hoque, and M. S. Anower, "A novel approach for flux weakening speed control of IPMSM drives," in Proceedings of the 3rd International Conference on Electrical \& Computer Engineering (ICECE '04), 2004.

[14] M. N. Uddin and F. Abera, "Efficiency optimisation based speed control of IPMSM drive," International Journal of Industrial Electronics and Drives, vol. 1, pp. 34-41, 2009.

[15] M. Meyer and J. Böcker, "Optimum control for interior permanent magnet synchronous motors (ipmsm) in constant torque and flux weakening range," in Proceedings of the 12th International Power Electronics and Motion Control Conference (EPEPEMC '06), pp. 282-286, September 2006. 
[16] P. Vaclavek and P. Blaha, "Interior permanent magnet synchronous machine field weakening control strategy-The analytical solution," in Proceedings of the SICE Annual Conference International Conference on Instrumentation, Control and Information Technology, pp. 753-757, August 2008.

[17] P. C. Krause, Analysis of Electric Machinery, McGraw-Hill, 1986.

[18] M. N. Uddin and M. A. Rahman, "Fuzzy logic based speed control of an IPM synchronous motor drive," in Proceedings of the IEEE Canadian Conference on Electrical and Computer Engineering, pp. 1259-1264, May 1999.

[19] R. Krishnan, Electric Motor Drives Modeling, Analysis, and Control, Pearson Education, 2001.

[20] D. Žarko, D. Ban, and R. Klarić, Finite Element Approach to Calculation of Parameters of An Interior Permanent Magnet motor, 2007.

[21] K. Zhou and D. Wang, "Relationship between space-vector modulation and three-phase carrier-based PWM: a comprehensive analysis," IEEE Transactions on Industrial Electronics, vol. 49, no. 1, pp. 186-196, 2002.

[22] M. N. Uddin, T. S. Radwan, and M. A. Rahman, "Performance of interior permanent magnet motor drive over wide speed range," IEEE Transactions on Energy Conversion, vol. 72, pp. 3133, 2002.

[23] P. Vaclavek and P. Blaha, "Interior permanent magnet synchronous machine field weakening control strategy-the analytical solution," in Proceedings of the SICE Annual Conference International Conference on Instrumentation, Control and Information Technology, pp. 581-586, August 2008.

[24] J. Xu, F. Wang, J. Feng, and J. Xu, "Flux-weakening control of permanent magnet synchronous motor with direct torque control consideration variation of parameters," in Proceedings of the 30th Annual Conference of IEEE Industrial Electronics Society (IECON '04), pp. 1323-1326, Busan, Korea, November 2004.

[25] Matlab, Simulink User Guide, 2009. 

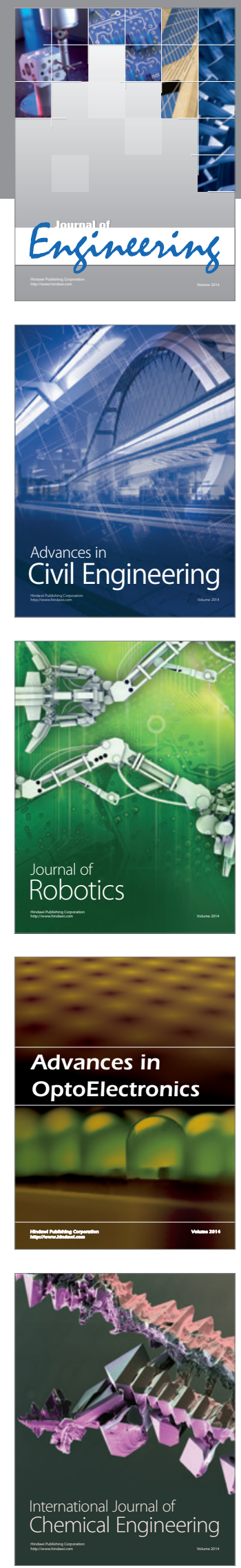

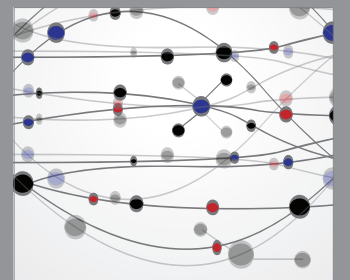

The Scientific World Journal
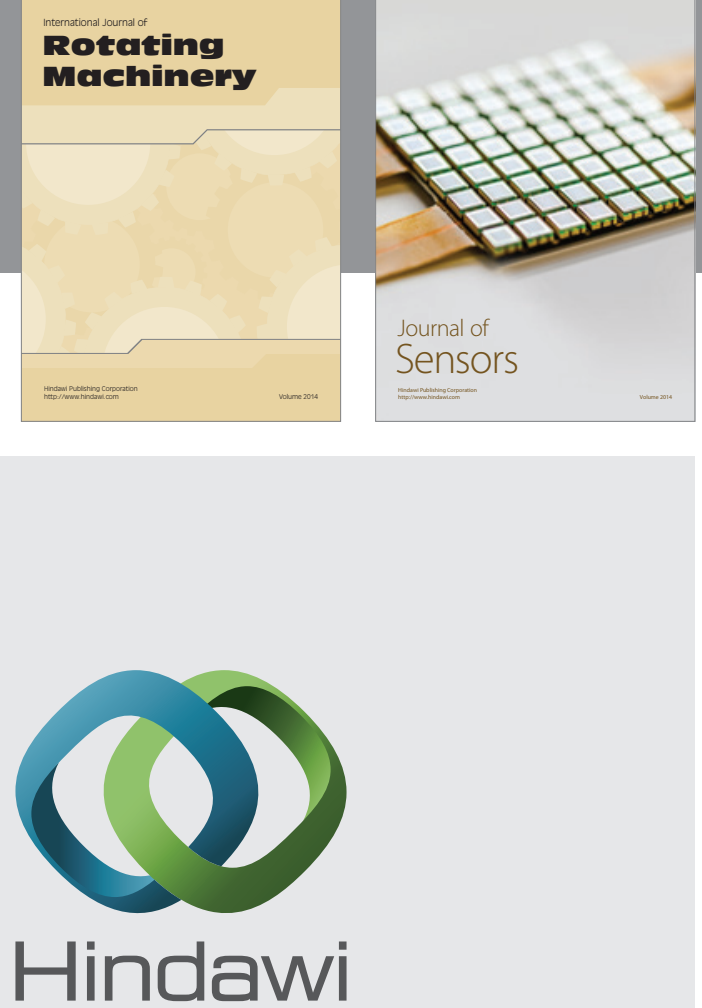

Submit your manuscripts at http://www.hindawi.com
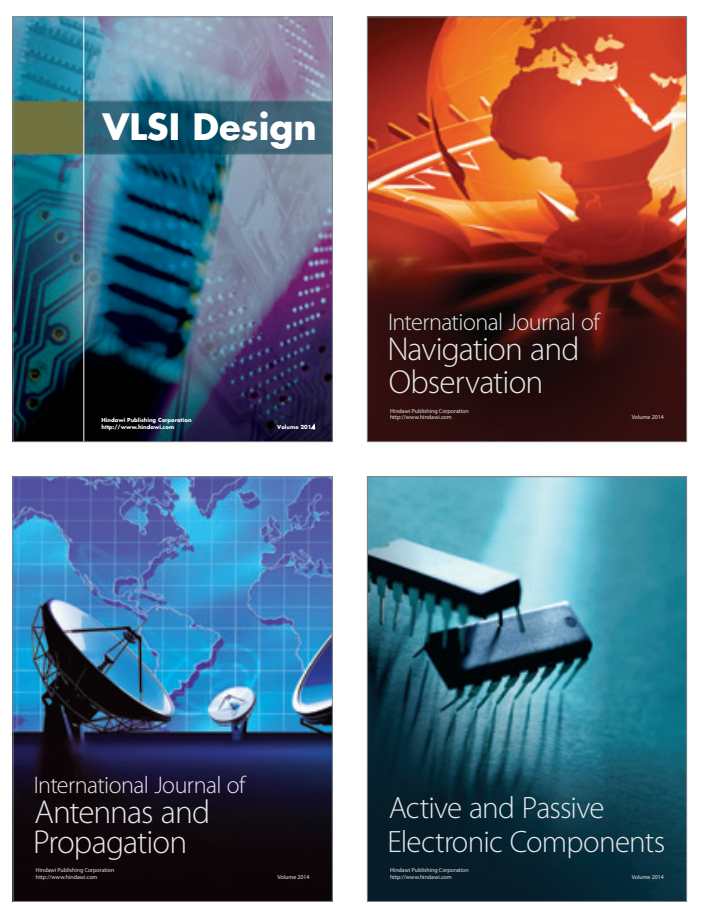
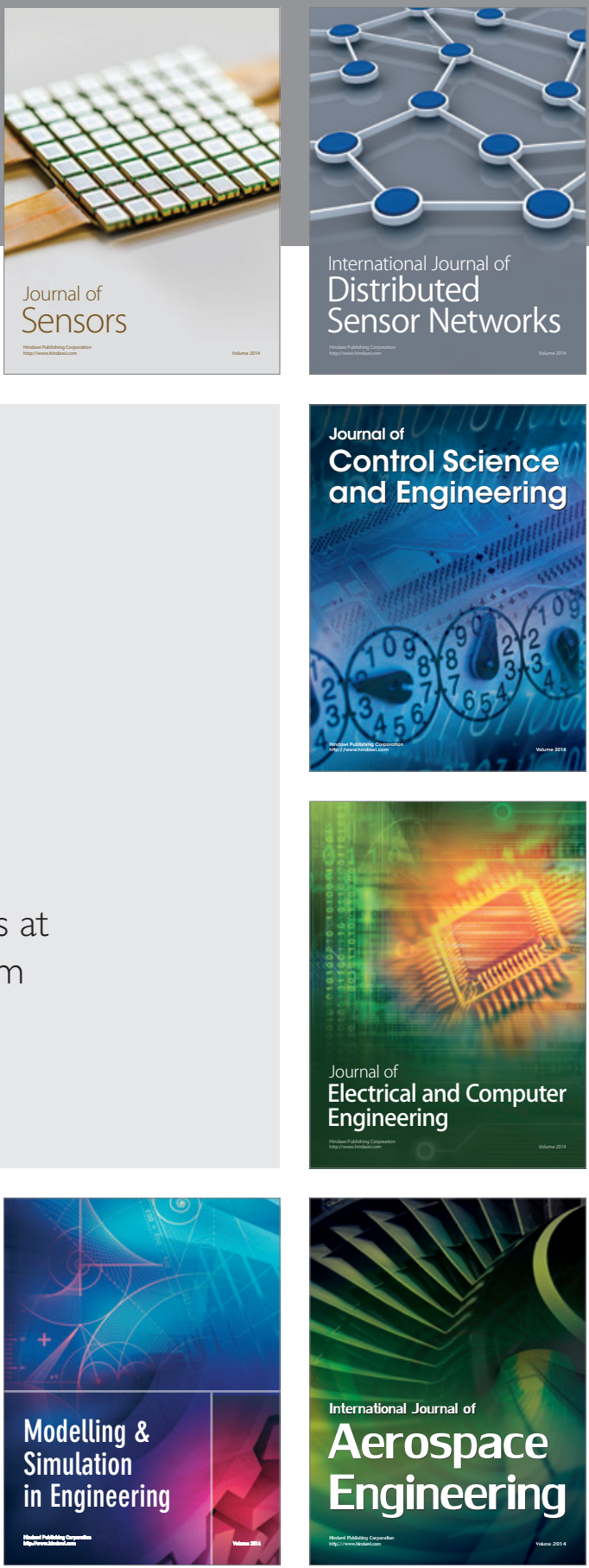

Journal of

Control Science

and Engineering
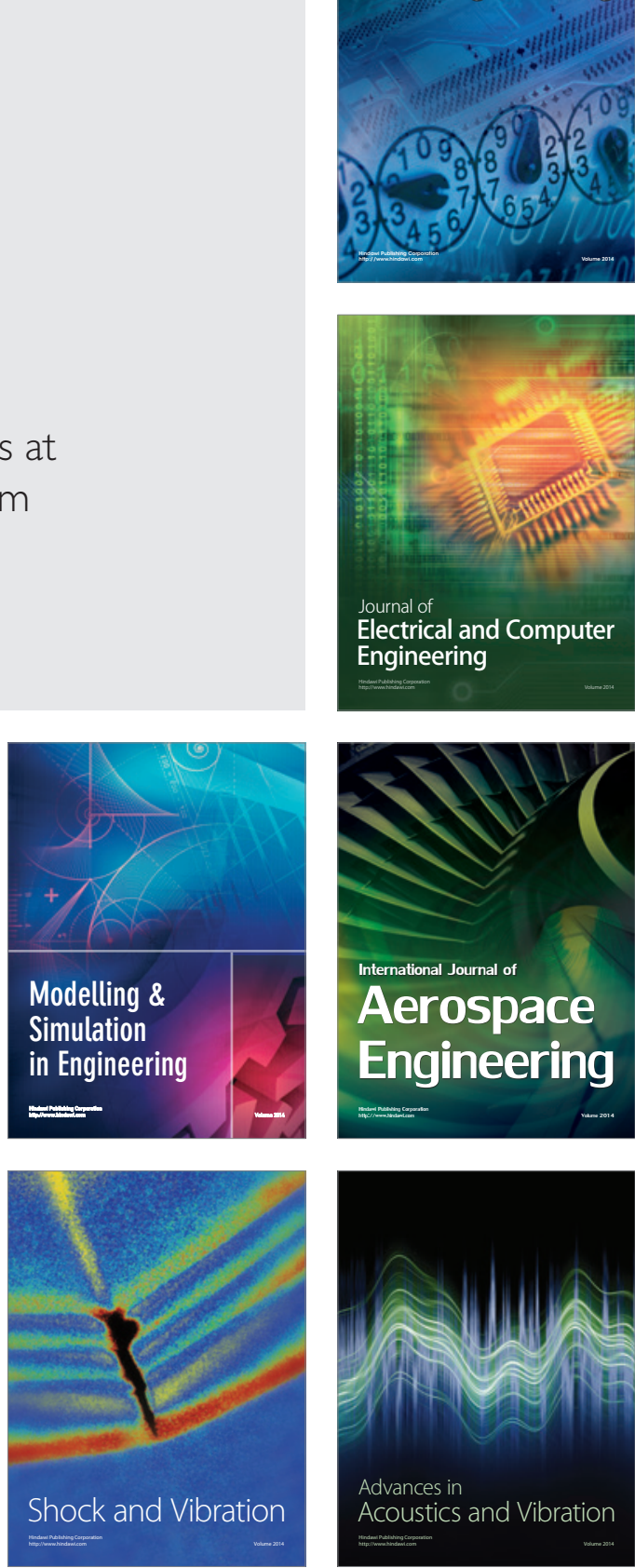